\author{
Sol Beatriz Calle \\ Velasco, Calle \& D’Alleman Abogados, Colombia \\ solcalle@iustic.net
}

\title{
Apuntes jurídicos sobre la proteccion de datos personales a la luz de la actual norma de habeas data en Colombia ${ }^{1}$
}

\begin{abstract}
The current statutory law, which was aimed at regulating the fundamental rights to privacy and information as set forth in the Colombian Constitution in articles 15 and 20, respectively, does not address this matter in general, despite repeated appeals by the Constitutional Court in this respect. Its origin and development basically focuses on financial and credit information and on maintaining this information at credit bureau agencies, thus imposing a series of burdens on the financial sector and hefty penalties for violation of this law. This paper makes a presentation about the origin of this fundamental right, provides evidence of the flaws of this law, underlines several aspects that could be inconvenient to the relations between Colombia and the European Union, and emphasizes issues that specifically have an impact on the banking system as the main source of credit and financial information in databases, which are now administered by credit bureau agencies.
\end{abstract}

Key words: Habeas data, electronic banking, right to information, right to privacy

\section{Introduccion}

La aplicación de la tecnología al tratamiento de datos personales es lo que ha justificado en muchos países la adopción de leyes que regulen y determinen, para el ciudadano, la forma de ejercer sus derechos; y para terceros, incluido el estado, los límites en el tratamiento de los mismos.

1 El presente artículo está basado en la ponencia presentada por la autora en el Primer Congreso Internacional de Derecho Informático llevado a cabo en la Universidad Externado de Colombia, en el mes de octubre del año 2006. 
En Colombia, después de la reforma constitucional del año 1991, se hizo una consagración expresa en el artículo quince de la Constitución del derecho a la intimidad como un derecho fundamental y se ha tratado de desarrollar este derecho a través de una norma estatutaria. Sin embargo, la precariedad y evidente parcialidad en el tratamiento del tema, por el Congreso de la República, no ha permitido el avance de una norma seria y comprensiva al respecto, teniendo en cuenta la realidad global que vive la empresa privada a través de Internet y, por ende, la forma como otros países han abordado el asunto.

Bajo tal perspectiva, es la pretensión de este trabajo esbozar, de manera general, cuál es el sentido y origen de las normas de protección de datos personales y cuál es la perspectiva de la actual ley 1266 de 2008 cuyo eje central es la información financiera, comercial, de servicios y la proveniente de terceros países.

El aporte que se pretende hacer con este escrito es un llamado a los medios académicos y, en general, a todos los ciudadanos para que adopten escenarios de intercambio de ideas con el fin de que se promueva el conocimiento y una verdadera discusión alrededor del derecho a la intimidad y a la protección de datos personales en el ámbito internacional, así como en Colombia, acorde con los planteamientos del Estado colombiano democrático y pluralista, con responsabilidad no sólo del mismo, sino también de los ciudadanos que lo conforman, a partir de la directriz general que la Corte Constitucional ha formulado en su sentencia C-1011 de 2008 sobre este tema.

\section{La proteccion jurídica del derecho a la intimidad a través de las normas de proteccion de datos de carácter personal}

El derecho a la intimidad tiene su génesis en las ideas liberales que inspiraron el individualismo del siglo XVIII. Pensadores como Locke y Mill plantearon en sus obras el reconocimiento de una libertad entendida como la facultad del individuo de disponer de todo cuanto le pertenece, de organizar la vida siguiendo el propio modo de ser sin injerencia de la sociedad o del Estado, aunque bajo el sometimiento de sus reglas (Murillo, 1990).

No obstante, la doctrina coincide en afirmar que la concepción del derecho a la intimidad, desligado de la idea de libertad y de otros derechos de la personalidad, se debe a la obra de dos autores norteamericanos: Samuel Dennis Warren y Louis Dembitz Brandais, cuando publicaron en diciembre 15 de 1890, en la Harvard Law Review, 5, un artículo que denominaron "The Right of privacy", es decir, "El derecho a la privacidad", a estar sólo (Suñe, 2000 : 31). De acuerdo con estos autores, los cambios en el sistema de vida de las personas, especialmente con la influencia de la tecnología, hacen necesario que el hombre se vuelva más sensible frente al perfeccionamiento de la cultura y, por ende, se percate de que su soledad e intimidad cobran cada vez mayor importancia. 
En consecuencia, la intimidad habrá de aparecer como un derecho autónomo e independiente en importantes instrumentos internacionales como: la Declaración Universal de Derechos Humanos de 1948, el Pacto Internacional de Derechos Civiles y Políticos de 1966, la Convención Europea para la protección de los derechos humanos y de las libertades fundamentales de 1950, entre otros. ${ }^{2}$

Pero como todas las declaraciones de derechos, la verdadera importancia de las mismas estriba en la posibilidad de que los titulares puedan hacer efectivos su derechos, puedan ejercerlos y exigir su reconocimiento. Tratándose del derecho a la intimidad el desenvolvimiento de las sociedades ha conllevado una transformación en éste derecho de la persona, pasando del determinismo individual a la autodeterminación informativa, como consecuencia del fenómeno tele-informático que va invadiendo todas las esferas de la vida moderna.

En efecto, la tecnología y su aplicación a sistemas de comunicación cada vez más avanzados, pone en evidencia la necesidad de controlar y regular el movimiento creciente de bases de datos de contenido personal, en algunas áreas sensibles de la sociedad, como lo son: la salud, el sistema financiero, la educación y lo judicial, entre otras.

La respuesta que gran parte de los Estados ha dado a esa necesidad de regulación se encuentra en las normas denominadas de protección de datos de carácter personal y, bajo esta perspectiva jurídica, el derecho a la intimidad cobra una inusitada importancia en el mundo de hoy bajo la conocida expresión del derecho al habeas data. ${ }^{3}$

En este marco de ideas, se esbozan de manera autónoma dos derechos que han forjado su autonomía a partir del derecho a la intimidad:

1. La protección de datos de carácter personal: que ha venido cobrando gran importancia en el mundo por tratarse de la forma a través de la cual se hace exigible el derecho a la intimidad y se pone freno a los abusos que, desde

2 Pacto Internacional de Derechos Civiles y Politicos (Ley 74 de 1968), Artículo 17.1: "[...] nadie será objeto de injerencias arbitrarias o ilegales en su vida privada [...]”. Convencion Americana Sobre Derechos Humanos, Pacto San Jose De Costa Rica ( ley 16 de 1972), Artículo 5.1: "Toda persona tiene derecho a que se respete su integridad física, psíquica y moral". Artículo 11.1: "Toda persona tiene derecho al respeto de su honra y al reconocimiento de su dignidad". Artículo 11.2: "Nadie puede ser objeto de [... ] ataques ilegales a su honra o reputación". Resolución de Asamblea General de la ONU \# 2.450 de 19 de diciembre de 1968 sobre "derechos del hombre y progresos de la ciencia y de la técnica". Documento E/CN 4/1142 1974, informe del secretario general de la comisión de derechos humanos sobre "aplicaciones de la electrónica que pueden afectar los derechos de la persona y límites que se deberían fijar para estas aplicaciones en una sociedad democrática".

3 Según Pérez: "Es notorio que las legislaciones mas sensibles a la defensa de las libertades han intentado ofrecer una respuesta jurídica eficaz a una de las exigencias más acuciantes que hoy gravita sobre la sociedad tecnológicamente avanzada: el respeto a la intimidad" (Pérez, 1996 : 317). 
la perspectiva tecnológica, puede significar el tratamiento de bases de datos personales. Este derecho ha sido reconocido por nuestra Corte Constitucional. ${ }^{4}$

2. Y, de otro lado, el derecho al habeas data: expresión de la autodeterminación informativa del individuo por la que ejerce plena disposición sobre sus datos. De hecho, en España se tiende a reconocer en el derecho de protección de datos un verdadero derecho fundamental independiente de la intimidad consagrada en el artículo 18.1 de la Carta fundamental de este país. ${ }^{5}$

Así, pues, la intimidad, entendida como autonomía física del individuo, ha dado paso a la intimidad informativa o autodeterminación informativa, de donde deviene precisamente su carácter fundamental, aspecto que se trata a continuación.

\section{El carácter fundamental del derecho a la intimidad}

La primera aparición constitucional del derecho a la intimidad se hace en Portugal en 1976 y, posteriormente, en la Constitución Española de 1978, con la invaluable consecuencia de tratarlo como un derecho autónomo y de rango fundamental, dadas su raíces en la dignidad humana, eje y motor de todos los derechos de la persona.

Los derechos fundamentales aparecen sin duda como una gran conquista de las actuales constituciones, máxime si se les concibe como "derechos humanos positivizados" (Alexy, 2003 : 26). Desde tal perspectiva, su gran importancia estriba en la posibilidad de aplicarse de manera inmediata como un control efectivo del individuo frente al Estado y frente a los demás individuos.

4 "Con las posibilidades que ofrecen hoy las modernas tecnologías de información y, en particular, los bancos de datos computarizados, ello equivaldría también a autorizar a la persona o entidad que recibe el dato a encarcelar 'virtualmente' en el banco de datos al sujeto concernido en los mismos. Lo cual, en países que carecen de una legislación específica protectora de la intimidad frente al fenómeno informático, favorecería abiertamente su cotidiana vulneración”. Sentencia de Tutela de enero 29 de 1993. Corte Constitucional. Magistrado Ponente Ciro Angarita Barón. 5 En una famosa sentencia del Tribunal Constitucional Español, la No. 292 del 30 de noviembre de 2000, la alta Corporación reconoció en la "protección de datos" un derecho fundamental diferente al de la intimidad que consagra el artículo 18.1 de la Constitución Española. En efecto, expresó el Tribunal: "Este derecho fundamental a la protección de datos, a diferencia del derecho a la intimidad del artículo 18.1 CE, con quien comparte el objetivo de ofrecer una eficaz protección constitucional a la vida privada personal y familiar, atribuye a su titular una haz de facultades que consiste en su mayor parte en el poder jurídico de imponer a terceros la realización u omisión de determinados comportamientos cuya concreta regulación debe establecer la ley. (....) La peculiaridad de este derecho fundamental a la protección de datos respecto de aquel derecho fundamental tan afín como es el de la intimidad radica, pues, en su distinta función, lo que apareja, por consiguiente, que también su objeto y contenido difieran”. 
Como consecuencia de lo anterior, se pone de relieve la importancia de saber si el desarrollo legal que debe tener el derecho a la intimidad debe hacerse desde la perspectiva individual de la libertad sin tener en cuenta los derechos sociales y colectivos o si, por el contrario, debe también preverse el ejercicio de la intimidad en el contexto social, en consonancia con estos otros derechos. La respuesta a este interrogante está directamente relacionada con la transformación que han padecido las sociedades con la implementación de la informática, como herramienta en el tratamiento de datos personales, lo que hace imperativa la referencia a este tema cuando se desarrollan leyes sobre la protección de datos.

Como corolario de lo anterior surge la necesaria relación entre "intimidad" y "expresión", como dos aspectos que colisionan y cuyos límites resultan de difícil delimitación.

\section{Autonomía del derecho a la intimidad frente a otros derechos de la personalidad}

Por tratarse de un derecho cuya génesis se encuentra en la dignidad humana y cuyo desarrollo se ha planteado por la doctrina internacional, a través del derecho a la autodeterminación informativa, el derecho a la intimidad es con frecuencia confundido con otros derechos que también devienen de la dignidad (Ferreira, 1982; Ruiz, 1995; Farinas, 1983).

La descripción conjunta del derecho a la intimidad, y de otros derechos de la personalidad, ha llevado a plantear la unidad que existe entre ellos como derivados de lo que se entiende como privacy (privacidad, intimidad). Esta descripción conjunta es clara en el artículo 15 de nuestra Constitución Política, que consagra tres derechos en la misma norma: la intimidad, el buen nombre y el habeas data.

Es posible, como lo afirma Perez Luño (1996), a propósito del artículo 18 de la Constitución Española, que la no alusión de derechos autónomos en su redacción, parece obedecer al propósito deliberado de seguir la tendencia, hoy dominante en la jurisprudencia y doctrina extranjera, de englobar en un derecho único y omnicomprensivo los distintos instrumentos de tutela jurídica de la vida privada.

Respecto de este tema, en el país es inequívoco el hecho de que las categorías de derechos que se refieren al honor, al buen nombre, a la imagen, entre otros, tienen una protección jurídica concreta, lo que no ha sucedido con el derecho a la intimidad como categoría autónoma.

En efecto, en la legislación colombiana diversas normas protegen estos derechos a través de reglamentaciones especiales. Algunas de ellas son de carácter penal, relativas a la injuria, la calumnia, la violación de correspondencia, la violación al domicilio, entre otras. Otras se encuentran en el derecho de autor que protegen la imagen de una persona, así como: las del derecho industrial 
que protegen los secretos industriales; las relativas a la reserva profesional en salud, la abogacía, e incluso las normas protectoras en el Código de comercio sobre los libros y la correspondencia del comerciante.

Si bien inicialmente no se hacía diferencia entre estos derechos, la Corte Constitucional colombiana ha concluido que el derecho a la intimidad es un derecho autónomo incluso del derecho al habeas data, entendido éste último como la facultad del individuo para rectificar, modificar, actualizar y, en términos generales, acceder a la información que sobre él se trate en una base de datos. ${ }^{6}$

En la sentencia SU-082 de 1995 la Corte comenzó a deslindar estos derechos y a plantear la autodeterminación informativa entendida como la facultad del titular de los datos para autorizar su conservación, uso y circulación de conformidad con las directrices legales. A partir de la sentencia T-552 de 1997 la Corte deslindó definitivamente los derechos a la intimidad y al hábeas data al afirmar que: "El derecho al hábeas data es, entonces, un derecho claramente diferenciado del derecho a la intimidad, cuyo núcleo esencial está integrado por el derecho a la autodeterminación informativa [...]".

\section{Intimidad versus información: colisión y delimitación}

El derecho a la información constituye también un derecho constitucionalmente consagrado en el artículo 20 de la carta política.

En términos ontológicos puede decirse que la información es un bien intangible que requieren los particulares, así como el Estado para el ejercicio de sus actividades y cumplimiento de sus fines.

La cuestión que se plantea es de límite: hasta dónde el uso y comunicación de esa información es pertinente a los fines que se pretende cumplir y cuándo viola la intimidad del individuo, partiendo de la afirmación de que no son incompatibles y que, bajo una concepción pluralista como la de la Constitución Colombiana, en la cual se encuentran plasmados derechos de corte liberal, de proteccionismo y bienestar social, se hace imperioso conocer y plantear el ejercicio de un derecho colectivo como la información y un derecho de corte individualista como la intimidad. Al respecto Pérez Luño plantea que:

6 Sentencia de junio 9 de 1993, Corte Constitucional. Magistrado Ponente Antonio Barrera Carbonel: "En un sentido amplio se admite, que al vulnerarse el derecho a la intimidad, se quebrantan otros derechos, los cuales por alguna parte de la doctrina se consideran como modalidades del derecho mencionado, pero que por voluntad de la constitución tienen su propia individualidad, como son el derecho al 'buen nombre', el 'habes data' y la 'inviolabilidad de la correspondencia'. Ciertamente la infracción al habeas data, supone en la mayoría de los casos, la violación del derecho a la intimidad. Sin embargo, no siempre, pues por vía de ejemplo, el no permitir a una persona que conozca las informaciones que sobre él se hayan recogido en un banco de datos y en archivos de entidades públicas y privadas, quebranta el derecho del 'habeas data', pero no el de intimidad". 
Lo cierto es que la información es poder y que sin ella cualquier gobierno moderno sería incapaz de cumplir sus fines. Pero con un uso indebido o abusivo de la tecnología informática por parte del ejecutivo o de determinados grupos privados se amenazaría de muerte al desarrollo de las instituciones democráticas; de ahí que se impongan fórmulas que garanticen su control social. (...) En todo caso sería muy provechoso para el estatuto de los derechos fundamentales una actitud del legislador, la judicatura y la doctrina tendente a extraer la mayor virtualidad posible de aquellos postulados de la norma constitucional, que sitúan en la noción de persona humana, en la integridad de sus necesidades y experiencias, el criterio hermenéutico básico para una práctica superadora de la fractura entre libertades individuales y derechos sociales. Entendiéndolo así, será posible un planteamiento correcto de las relaciones informática-intimidad, asentado sobre el principio de que libertad e igualdad, individuo y colectividad, no constituyen opciones excluyentes (1995: 339).

En diversas sentencias la Corte ha planteado la colisión que se presenta entre ambos derechos: intimidad e información. El contexto en el cual quizás cobra más importancia la planteada colisión, tiene que ver con la información de los datos crediticios o de solvencia patrimonial de una persona a través de las centrales de crédito. En este escenario, no obstante la Corte ha reconocido en el interés general una razón que justifica la limitación a la intimidad, ${ }^{7}$ cada caso concreto plantea la necesidad de estudiar si puede limitarse o no la intimidad del individuo so pretexto del interés general. ${ }^{8}$ Este estudio debe llevar a determinar lo que la Corte denomina el núcleo esencial del derecho, es decir, aquella parte de su contenido que es absolutamente necesario para que los intereses jurídicamente protegidos resulten real, concreta y efectivamente tutelados.

El interés general parece ser, entonces, el denominador común que acoge la doctrina sobre el tema para fijar los límites del derecho a la intimidad. La cuestión que secundariamente se suscita es la determinación de lo que una sociedad en particular entiende por interés general (Iturralde, 2000). Un aspecto más que

7 Sentencia de tutela de enero 29 de 1993. Corte Constitucional. Magistrado ponente Ciro Angarita Barón.

8 Sentencia de abril 26 de 1993. Corte Constitucional. Magistrado ponente Eduardo Cifuentes Muñoz: "El ejercicio de los derechos a informar (CP art 15 y 20 ) y a la intimidad (CP art 15) plantea en la práctica constantes controversias entre sus titulares. Mientras que los centros de información buscan hacer públicos ciertos datos en función de diversas necesidades - transparencia, seguridad, previsibilidad,etc.-, las personas, en un mundo altamente sistematizado, procuran mantener un ámbito mínimo de privacidad. Desde una perspectiva jurídica, la solución a este conflicto depende de la existencia de claros límites constitucionales y de criterios objetivos que permitan sopesar el alcance de los derechos fundamentales en un caso concreto". 
legitima la necesidad de que el derecho a la intimidad sea autónomamente desarrollado a través de la norma respectiva.

\section{Perspectiva en Colombia}

Bajo la vigencia de la Constitución de 1886, el derecho a la intimidad no estuvo consagrado en el país como un derecho autónomo. Solamente a partir de algunos fallos de la Corte Suprema de Justicia y del Consejo de Estado, mas de aquella que de éste, sobre materias aledañas al derecho a la intimidad (intercepción de comunicaciones, violación del domicilio) se concluye por algunos autores la necesidad de defender en Colombia éste aspecto del individuo (Cepeda, 1992).

Fue en la Constitución de 1991 en donde vino a consagrarse de manera expresa e independiente el derecho a la intimidad y el habeas data, después de las diversas discusiones y modificaciones que la norma tuvo en las comisiones en el interior de la Asamblea Constituyente. Su justificación estuvo fincada, precisamente, en la existencia de bases de datos de morosos o crediticias que, aunadas a los avances de la tecnología, dejaban en riesgo la intimidad y derechos de los individuos (Cepeda, 1992).

La consagración de la intimidad como derecho fundamental en nuestro país estuvo sin duda inspirada en las normas internacionales que en tal sentido la han reconocido y de cuya redacción pareciere haberse tomado el artículo 15 de la carta política en donde quedó plasmado.

Como derecho fundamental, la custodia del mismo ha estado a cargo de la Corte Constitucional. En diversas sentencias la Corte ha definido y se ha referido a la protección de datos personales y no en pocas esta corporación ha insistido en la necesidad de una reglamentación del artículo 15 de la Constitución, especialmente por la nueva perspectiva desde la cual se viene tratando la intimidad en otros países, respondiendo fundamentalmente a los avances de la teleinformática.

Respondiendo a este llamado, fueron numerosos los intentos de regulación del derecho a la intimidad. Antes de la expedición de la Constitución Política de 1991, cabe destacar el proyecto de ley No. 73 de 1986, por el cual se pretendía crear un estatuto para proteger la intimidad de las personas frente a los sistemas de información y los bancos de datos. Este proyecto tuvo como génesis el estudio realizado por los centros de investigación de las facultades de ingeniería y administración de la Universidad de Los Andes, investigación realizada con el patrocinio del Centro Latinoamericano de Recursos Humanos e Informática de la Presidencia de la República.

Después de la expedición de la Constitución de 1991 se pretendió regular el artículo 15 de la Constitución Política a través de proyectos como el número 070 de 1997 (Cámara), que buscaba proteger la intimidad personal y el buen 
nombre frente a los sistemas de información y los bancos de datos. Le siguieron los proyectos de ley estatutaria números 115 de 1997 (Senado); 52 de 2000 (Senado) y 124 de 2001 (Cámara), que pretendían desarrollar el artículo 15 de la Carta y regular la actividad de tratamiento de datos personales por parte de los bancos de datos.

Obedeciendo a distintos factores, todos estos intentos resultaron fallidos.

Muchos de estos proyectos, y los posteriores, fueron liderados por el sector bancario, que ha sido pionero en el uso de la informática y sistematización de su actividad, pues en ello va comprometida la seguridad que debe otorgarse al usuario y la necesidad de dar uniformidad a todas sus prácticas, en todos los países del mundo.

Para el sector financiero la regulación de las bases de datos de sus clientes es un imperativo en el desarrollo de su labor. La ausencia de la misma conlleva, sin duda, a que sea discrecional del funcionario de turno la adecuada práctica que se haga sobre el manejo y tratamiento de la información contenida en esas bases de datos.

Así se exponía el tema en 1984, para éste sector: "frente a esta realidad la banca debe o desconocer el tema y esperar que se promulguen leyes al respecto, o tomar la iniciativa y conducir a acuerdos interbancarios para definir la dinámica de estas relaciones" (Peña, 1984 : 74).

Merece especial mención el proyecto de ley estatutaria No. 64 de agosto de 2003 y 143 de 2003, presentado por la Defensoría del Pueblo, pero finalmente archivado. Estos proyectos pueden considerarse como los más serios intentos de regulación de la materia que se ha hecho en el país.

En su contenido resaltaba aspectos de gran importancia: un ámbito de aplicación para toda recolección de datos, destacando la necesidad de que el uso de la informática debía sujetarse al respeto de los derechos humanos y fundamentales. Ampliaba la gama de principios que deben inspirar el tema de la protección de datos: autodeterminación informativa, calidad, proporcionalidad, transparencia, confidencialidad, respeto al buen nombre, caducidad, seguridad, gratuidad, contradicción, debido proceso, entre otros.

Creaba una acción denominada "procedimiento de amparo informático" dirigida a la protección del derecho al acceso y habeas data. Definía el dato personal de manera general como el objeto de protección por la ley, diferente al llamado dato sensible. Determinaba como autoridad de control de la aplicación de la norma a la Defensoría del Pueblo, la cual tendría dentro de sus funciones la de llevar el registro nacional de datos y la de autorizar a los operadores de bases de datos, previo el cumplimiento de los requisitos exigidos por la ley.

Contemplaba disposiciones sectoriales para diferentes tipos de bases de datos como son: bases de datos de naturaleza pública, de la fuerza pública, policía judicial y organismos de seguridad del Estado, de suscriptores de servicios públicos 
domiciliarios, de naturaleza privada, de información sobre solvencia patrimonial y financiera, con fines de publicidad y ventas. Consagraba una adición a la Ley 599 de 2000 o Código Penal, al consagrar como delito el tratamiento ilegal de datos cuando se ejerce la actividad sin autorización, o sin consentimiento del titular, o desconociendo la finalidad de la recolección del dato.

Definía una pena de 6 meses a 6 años y preveía la presunción de culpa, en cabeza del operador de las bases de datos, cuando el titular accede a la jurisdicción ordinaria para obtener resarcimiento de perjuicios y aquel fue encontrado culpable ante la Defensoría del Pueblo a través del procedimiento de amparo informático, que por lo demás, es incompatible con la acción de tutela.

Reglamentaba bases de datos especiales cuando se trata de los llamados datos sensibles, así como el derecho al olvido o tema de la caducidad de los registros en las bases de datos, excluyendo de ellos los datos del co-deudor, y distinguiendo diversos escenarios sujetos al inicio de acciones judiciales, la finiquitación de las mismas, el pago inmediato del deudor, entre otros.

Desafortunadamente, para el país, estos proyectos no continuaron su curso en el Congreso y, como resultado de ello, se presentó en la legislatura del año 2006 uno nuevo, producto de diversos acuerdos entre los congresistas y con la urgencia de que el país adoptase un estatuto sobre el habeas data, especialmente con los proyectos de inversión extranjera que requiere el Estado.

\section{El proyecto de ley 027 de 2006 y la ley 1266 de 2008}

La preocupación fundamental de los ponentes del proyecto que, finalmente, dio lugar a la actual ley de habeas data, estribaba en la necesidad de que se regulase el tema de la inclusión de morosos en las bases de datos de las centrales de riesgo y no se vulneraran los derechos de los ciudadanos en este sentido. De allí que el título mismo de la norma otorgue especial mención a la regulación de la información financiera, crediticia y comercial, aspecto que evidencia la colisión que se planteaba en anteriores líneas: el derecho de información de las entidades del sector financiero respecto del comportamiento crediticio de los ciudadanos y el derecho a la intimidad de éstos, específicamente de la protección de sus datos personales cuando están vinculados con el sector financiero.

Se hace entonces necesario precisar que una cosa es la información comercial, crediticia o financiera de una persona, que considerada en sí misma puede no incluir datos de carácter personal (por ejemplo, estadísticas en comportamientos de consumo de tarjetas de crédito) y otra que los datos personales de una persona física revelen su comportamiento financiero y, con base en ellos, se tomen decisiones desiguales o abusivas, especialmente cuando tales datos son tratados por sistemas informáticos.

Frente al fenómeno de lo que hoy conocemos como banca electrónica, es decir, el ejercicio de la banca a través de medios electrónicos (iacaso banca 
digital hoy día?), resulta de gran impacto la forma como se regula la información financiera, definida en la ley como: "[...] aquella referida al nacimiento, ejecución y extinción de obligaciones dinerarias, independientemente de la naturaleza del contrato que les dé origen”. Bajo tal criterio, y frente al poder de la informática, se determinan una serie de lineamientos para las entidades del sector que, finalmente, pueden asumir diversos roles en los términos de las definiciones dispuestas por la norma.

Dentro de tales roles, importantes en su determinación al momento de guiar la interpretación de la ley y el desarrollo posterior de la misma, se consagran escasos parámetros sobre los términos específicos de la protección de datos y se hace énfasis en las de: "fuente", "operador" y "usuario" de la información, con la particularidad de estar referidas especialmente a las instituciones financieras, las cuales pueden enmarcarse, inicialmente como fuentes y usuarias, con las responsabilidades y deberes que la ley prevé en ejercicio de estos roles.

Si todo el ejercicio de la actividad financiera se concibe hoy a través de medios electrónicos, menester será reconocer que en el ejercicio de la misma existe un riesgo mayor de vulnerabilidad hacia el derecho fundamental de la intimidad y, de forma mas certera, frente a la protección de datos personales y el ejercicio del habeas data por parte de los ciudadanos.

Desde esta perspectiva surgen directrices importantes para el ejercicio de la actividad financiera: la seguridad informática en relación con sus sistemas, la seguridad de la información de sus usuarios y clientes, y el respecto por la debida gestión de datos de carácter personal que involucra derechos fundamentales constitucionales.

Sin embargo, la norma se quedó corta, y de manera parcial, hace relación a una serie de conceptos que si bien coinciden en algunos aspectos con el desarrollo jurisprudencial en la materia, no tienen la suficiente entidad para hacer un tratamiento jurídico global del tema, a pesar de su importancia constitucional.

La norma colombiana define el dato público, semi-privado (dentro del cual se califica al crediticio) y el privado, sin mencionar el dato sensible que compromete la información sobre religión, raza, sexo, política y demás asuntos que atañen al individuo y que, sin duda, pueden ser objeto de tratamiento para la construcción de perfiles de consumo, por ejemplo.

Al hacer referencia a los principios del tratamiento de datos, introduce un principio denominado interpretación integral de derechos constitucionales, aspecto que en estricto derecho compete a los jueces en su función de aplicar e interpretar la Constitución y la ley. Esto tiene relevancia especialmente en la relación que se ha planteado entre habeas data e información, conflicto de derechos fundamentales que no ha sido fácil de resolver y que requiere apelar a herramientas de interpretación constitucional como lo es el principio de 
la proporcionalidad, principio que sí era mencionado en el proyecto 064 de la Defensoría del Pueblo, antes reseñado.

Por otro lado, y como un principio independiente de los relacionados sobre el tratamiento de datos personales, incluye uno nuevo denominado "favorecimiento a una actividad de interés público", referido este a la actividad financiera.

Ninguna claridad aporta la inclusión de este principio, máxime si lo que se pretende es legislar sobre una forma de resolver los conflictos que puedan presentarse entre intimidad e información, concretamente cuando se trata de datos personales de carácter financiero o crediticio. Es función del Juez Constitucional, especialmente, determinar cuándo debe primar uno u otro derecho, dependiendo del caso y situación planteada; y no resulta de manera idónea ni legal afirmar que, por el principio de favorabilidad aquí consagrado, debe resolverse un conflicto en pro de favorecer una actividad de interés público, concretamente la financiera.

Sobre el principio del consentimiento, eje y columna vertebral de la protección de datos en la mayoría de legislaciones del mundo, no se hace ninguna mención expresa y solamente se refiere al mismo en diferentes apartados y para concretos eventos de disposición de datos. No obstante, y acorde con el pronunciamiento de la Corte Constitucional en la sentencia C-1011 de 2008, es necesario que la fuente (entidades financieras frente a sus clientes) obtenga el consentimiento claro, expreso y concreto al fin propuesto para el tratamiento de datos y su inclusión en centrales de riesgo, con una carga adicional: certificar la obtención de dicho consentimiento frente a los operadores y usuarios de los datos.

Con relación a la exigencia que se hace a los operadores de la información, en cuanto a la necesidad de adoptar las medidas técnicas necesarias para conservar la información y garantizar su seguridad, el proyecto no menciona cuales serían esas medidas técnicas, ni define los niveles de seguridad que se deben adoptar, según el tipo de información recabada, tal como se ha consagrado en otras legislaciones, como por ejemplo la española. La importancia de determinar estos niveles de seguridad y de prever la concreción de tales medidas, estriba en que justamente esa seguridad es la que garantiza al ciudadano que sus datos no serán objeto de "saqueo" y que los sistemas informáticos adoptados, cumplen con estándares de talla internacional, para la transferencia de datos entre empresas y/o gobiernos de diferentes países.

Para las entidades financieras se consagran una serie de exigencias, dada su calidad de fuente y usuaria de la información. Exige por ejemplo, a las fuentes de la información, hacer una actualización mensual de la misma cuando ésta es prodigada a un operador y establece una especie de procedimiento adicional antes de reportar un dato negativo, en el sentido de dar aviso al titular de la 
información para que este pueda controvertir el dato negativo, o proceder a su pago. Estas cargas y deberes implican para la banca una actualización y promoción de tecnología que les permita implementar estos nuevos procesos en su interior, al igual que deberán hacerlo las entidades de control, en este caso la Superintendencia Financiera y la de Industria y Comercio.

Ahora bien, una mirada retrospectiva de la norma a la luz de lo que ha determinado la Corte Constitucional en sus múltiples sentencias sobre el tema, a propósito de la acción de tutela, permite afirmar que todo lo que se ha indicado como contenido de la ley ya había sido objeto de precisión por la Corte vía jurisprudencia constitucional y, por ende, ya estaba vigente en el país. De allí que en términos generales el aspecto novedoso de la ley puede ser el planteado en relación con el incumplimiento, control y sanciones que pueden ser impuestas a los responsables del tratamiento de datos personales en Colombia y quienes hagan una manipulación o uso indebido de los mismos. No de otra forma podría garantizarse que el lucro obtenido con el uso de este tipo de información se viera truncado por las sanciones pecuniarias que acarrean la violación de la norma.

Consecuente con eso el proyecto incluyó unas sanciones de carácter únicamente pecuniario, que se aplican frente a la violación de la norma tratándose de información comercial, financiera, crediticia y de servicios. Tales sanciones se imponen a las fuentes, operadores y usuarios de la información financiera, a través de un procedimiento no especificado en sus lineamientos generales, por lo menos. Ahora bien, estas sanciones se ven agravadas con la expedición de la Ley 1273 de 2009 en Colombia que de manera expresa erige como delito "la violación de datos personales" en su artículo 269 F, situación que acentúa la responsabilidad del sector financiero en el tratamiento de estos datos.

Tratándose de las multas pecuniarias que impone la ley 1266, no podría pensarse en una aplicación analógica de la norma a otros tipos de operadores de bases de datos de carácter personal, distintos a los de la información financiera. Ello traería como consecuencia la inocuidad de la norma para todos los demás administradores de bases de datos que quedarían por fuera de estas sanciones pero con la posibilidad de que si pueda serles aplicable la norma de carácter penal.

Preocupa que no se hace referencia expresa a la transferencia internacional de datos, solo una mención tangencial, exigiendo para los entes colombianos hacer transferencia de datos a países que garanticen el mismo nivel de seguridad que la que prodiga el proyecto para sus nacionales. Sin embargo, la preocupación real es la de saber si con esta ley Colombia puede en efecto afirmar que posee el mismo nivel de seguridad que las legislaciones extranjeras prodigan a sus ciudadanos, especialmente la Europea, a propósito de los intentos por traer inversión de los países de la Unión Europea a Colombia.

En su parte final, la ley prevé una situación transitoria para los deudores del sistema financiero y otorga un plazo de 6 meses para que los entes de control 
(superintendencia financiera y de industria y comercio) adapten sus procesos a la misma. La función de control en instituciones estatales que no resultan ser independientes, como lo son las superintendencias, cuestiona la ley y la imparcialidad que pueden asumir estos entes al momento de ejercer control respecto de bases de datos públicas y sus administradores de igual o mayor jerarquía.

Finalmente la ley fue declarada constitucional por la Corte mediante sentencia 1011 del 16 de octubre de 2008, con ponencia del magistrado Doctor Jaime Córdoba Triviño.

La sentencia de la Corte, no obstante, declaró inexequibles algunos de sus artículos y condicionó la constitucionalidad de otros; adolece de un lenguaje ambiguo que en algunos apartes deja entrever la preocupación de la Corporación por el desarrollo estatutario parcial que se hizo del artículo 15, al entender que la ley regula de manera exclusiva los datos personales de carácter crediticio, financiero, comercial, de servicios y la proveniente de terceros países, y la realidad de las demás bases de datos que, de acuerdo a lo expresado por la Corte, están reguladas bajo los criterios que ella misma ha determinado desde el año 1992 hasta la fecha, e incluso por lo dispuesto en la ley estatutaria siempre que proceda una interpretación analógica.

La aplicación de la norma y la apertura de escenarios académicos alrededor del tema serán los factores clave en el desarrollo de estos derechos fundamentales en Colombia sin que se tornen en normas sectoriales y de beneficio puntual para algunos.

\section{Reflexión final}

Al pensar sobre el individualismo concebido bajo el pensamiento liberal del siglo XVIII, que sustenta desde entonces el derecho a la intimidad y su confrontación con lo público. Aunado a ello la ausencia de interés por parte del estado en una regulación seria sobre el tema, se llega a la conclusión de la crítica situación en la que se encuentran los ciudadanos colombianos, desprovistos de todo conocimiento sobre el tema, que solamente cobra vigencia e importancia en la medida en que el advenimiento de la informática genera mayores riesgos en el tratamiento de sus datos y su ilícita circulación por el mundo.

No solo los países europeos sino, también, países latinoamericanos como Argentina, Chile y recientemente México, han dado respuesta a esta preocupación a través de normas reguladoras de la protección de datos de carácter personal, normas que en sus contenidos presentan una regulación completa sobre el tema pretendiendo establecer parámetros para los responsables de los ficheros y crear los procedimientos a través de los cuales los ciudadanos puedan ejercer la actual faceta del derecho a la intimidad: el habeas data o 
la facultad de autodeterminación sobre la propia información, que terceros manipulan en bases de datos informatizadas.

Desde la perspectiva económica global en la que, independiente de cualquier consideración sobre su conveniencia o no, se encuentra inmersa Colombia es fundamental determinar una norma integral de protección de datos, especialmente cuando las directrices de los países con mayor desarrollo económico incluyen la exigencia de un nivel de protección por lo menos igual para los ciudadanos cuyos datos son "importados" al país. Las implicaciones de este intercambio internacional de datos han pasado desapercibidas incluso para el Gobierno colombiano cuando transfiere los datos de 31 millones de colombianos a una empresa "comercializadora" de los mismos.

Al respecto resulta pertinente traer a colación lo que sostiene Pérez Luño sobre este tema:

La necesidad de tutelar la vida privada de los individuos ha rebasado, en los últimos años, la esfera estricta del derecho interno para plantearse como una exigencia del orden jurídico internacional. [...] Uno de los aspectos de mayor interés en la reglamentación jurídica de la informática a escala internacional es el que se refiere a la transmisión de datos personales entre diversos países. El problema del flujo transnacional o internacional de datos ha suscitado un abierto conflicto de intereses entre los países productores y los países consumidores de datos informáticos. Los países tecnológicamente avanzados se hallan en condiciones de recoger informaciones, almacenarlas y distribuirlas con la utilización de la informática. Por el contrario los países subdesarrollados sólo pueden recibir y consumir informaciones; es más, en determinados casos ni tan siquiera pueden servirse de ellas por carecer de los medios técnicos necesarios para aprovecharlas. Esta circunstancia ha determinado que los países desarrollados mantengan una posición decidida a favor de una libertad ilimitada de intercambios de informaciones entre todos los países; mientras que los países subdesarrollados, que carecen de una tecnología informática propia, exigen que se reconozca la facultad de ejercer un control sobre los datos que puedan recogerse en su territorio (Pérez, 1995 : 354).

Si bien un proyecto de ley estatutaria no está llamado a efectuar una regulación exhaustiva del derecho fundamental que desarrolla, sí es necesario que el reglamente los aspectos esenciales del mismo, orientación de la cual se aleja la ley que finalmente fue aprobada por el Congreso y que pretende reglamentar en lo esencial el derecho a la intimidad y a la información.

Ello advierte la sentida necesidad de que la comunidad académica, desprovista de intereses particulares, haga presencia y apoye buenas iniciativas sobre la regulación de este tema, bajo el contexto ineludible en el cual se encuentran 
los abogados en el país: el desarrollo y la prelación de una constitución que, inspirada en el pluralismo, consagra derechos de corte individual, social y colectivo, que exigen ser puestos en marcha bajo una dinámica interpretativa conciliadora, que efectivamente responda a los intereses de toda la ciudadanía.

En tal propósito descansa la intención de estos apuntes que no pretenden hacer un análisis exhaustivo del tema sino dejar en evidencia la situación jurídica que los derechos constitucionales de la intimidad, protección de datos y habeas data tienen hoy en Colombia: una regulación ambigua a través de una norma estatutaria parcial, la jurisprudencia de la Corte Constitucional con mas de 140 sentencias sobre el tema y una norma penal que convierte en delito la violación de los datos de carácter personal. El debate está abierto.

\section{Referencias}

Alexy, R. (2003). Tres escritos sobre los derechos fundamentales y la teoria de los principios. Serie de Teoría Jurídica y Filosofía del Derecho, No. 28. Bogotá: Universidad Externado de Colombia.

Alvarez, J. A. (2000). "Los comerciantes y la Constitucion de 1991. Proyecciones sobre la actividad mercantil del derecho a la intimidad y el derecho de asociacion". Revista de Derecho Privado, 13.

Angarita, B. (1990). "Hacia la regulacion de los bancos de datos personales: una experiencia colombiana”. Derecho y Tecnología Informática, 4.

Cancino, A. (1990). "La informatica y el derecho a la intimidad". Revista de la Academia Colombiana de Jurisprudencia, pp. 290-291. Cepeda, M. J. (1992). Los derechos fundamentales en la constitucion de 1991. Bogotá: Temis.

Delpiano, H. M. (1997). Protección de datos personales. Bancos de datos de informacion creditica. Montevideo: Fundación de Cultura Universitaria.

De la Calle, J. M. (2009). Autodeterminación informátiva y habeas data en colombia. Temis: Bogotá.

"Derecho a la intimidad". Foro Colombiano, 24.

Escobar, E. M. y Otálvaro, L. F. (1995). El derecho a la intimidad en colombia. Medellín: Quirama.

Fariñas Matoni, L. M. (1983). El Derecho A La Intimidad. Madrid:Trivium.

Ferreira, D. M. (1982). El derecho a la intimidad. Buenos Aires: Editorial Universidad. Buenos Aires.

Gutierrez, J. D. (2001). Los límites entre la intimidad y la informacion. Bogotá: Universidad Externado de Colombia. 
Iturralde, M. (2000). "La libertad de informacion frente al derecho a la intimidad: el dilema entre una sociedad informada y el derecho a la soledad”. Revista Tutela, Acciones Populares y de Cumplimiento, 7.

Madrid-Malo, M. (1994). "Derecho a la intimidad". Su Defensor, 9.

Rivera, A. (1985). "La libertad, el derecho a la intimidad y la informatica". Prisiones, 11.

Murillo, P. L. (1990). El derecho a la autodeterminacion informativa. Madrid: Tecnos.

O'callaghan, X. (1991). Libertad de expresión y sus límites: honor, intimidad e imagen. Madrid: Editorial de Derecho Reunidas.

Peña, G. (1984). Informatica, derecho bancario y derecho a la intimidad. Bogotá: Fundación Jurídica Colombiana, Universidad de los Andes.

Perez Luño, A. (1995). Derechos humanos, Estado de derecho y Constitución. Madrid: Tecnos.

Ruiz, M. C. (1995). La configuracion constitucional del derecho a la intimidad. Mdrid: Tecnos.

Suñe, E. (2000). Marco jurídico del tratamiento de datos personales en la Union Europea y en España. Madrid: Ceessj Ramón Carande, Universidad Complutense. Madrid.

\section{Sentencias}

Corte Constitucional, Sala plena. Sentencia C-008 de 1995.

Corte Constitucional, sala primera de revisión. Sentencia de junio 16 de 1992.

Corte Constitucional. Sentencia de Tutela de julio 7 de 1992. Magistrado ponente: Alejandro Martínez Caballero

Corte Constitucional. Sentencia de Tutela de enero 29 de 1993. Magistrado Ponente: Ciro Angarita Barón.

Corte Constitucional. Sentencia de Tutela de abril 26 DE 1993. Magistrado Ponente Eduardo Cifuentes Muñoz.

Corte Constitucional. Sentencia de Tutela de junio 9 de 1993. Magistrado ponente: Antonio Barrera Carbonel.

Corte Constitucioal, sala plena. Sentencia de control constitucional de noviembre de 1993. Magistrado ponente: José Gregorio Hernández Galindo. 
Corte Constitucional, Sala Primera de Revisión. Sentencia de revisión de tutela T-414 de junio 16 de 1992. Magistrado ponente: Ciro Angarita Barón.

Corte Constitucional. Sentencia de Tutela T-11 de mayo 22 de 1992.

Tribunal Constitucional Español. Sentencia TC- 292 del 30 de noviembre de 2000.

Corte Constitucional. Sentencia 1011 del 16 de octubre de 2008. Magistrado ponente Jaime Córdoba Triviño.

\section{Normas jurídicas}

Constitucion Politica De Colombia de 1991, Comentada y titulada por: Sachica, L. C.. Editorial DIKE. Bogotá.

Convenio 108 del 28 de Enero de 1981 de los Estados miembros del Consejo de Europa, para la protección de las personas con respecto al tratamiento automatizado de datos de carácter personal.

Directiva 95/46/CE del Parlamento Europeo relativo a la protección de las personas físicas en lo que respecta al tratamiento de datos personales y a la libre circulación de esos datos.

Ley estatutaria 1266 de 2007.

Proyecto de ley estatutaria No. 12/93, Senado, 127 de 1993.

Proyectos de ley estatutaria No. 71 y 75 Senado de 2002

Proyecto de ley estatutaria 064 de Agosto de 2003 